\title{
Research into Genetically Modified Organisms in New Zealand: An Examination of a Sociotechnical Controversy
}

\section{SARAH EDWARDS}

Department of Environmental Management, Lincoln University, Lincoln, Canterbury, New Zealand

Email: sarah.edwards@lincoln.ac.nz

ABSTRACT New Zealand is known around the world as a country that is clean, green and "100\% Pure." The existence of genetically modified organisms in New Zealand is generally viewed as inconsistent with this identity, and there is therefore considerable public controversy surrounding research that utilises genetic modification techniques. In this paper, I examine the variety of interacting factors that are serving to shape this controversy, the influence it is having on research practices, and the implications for future risk management policy.

\section{KEY MESSAGE}

Students will gain a nuanced understanding of the controversy over research into genetically modified organisms (GMOs) in New Zealand. They will learn that this controversy (1) involves interactions between a wide variety of factors, including legislation, decision-making processes, formal methods of public consultation, and GE-Free activism; (2) predominantly focuses on outdoor GMO research; and (3) is diverting attention away from other forms of GMO research, especially research conducted indoors. This detailed examination will enable students to learn how this controversy is serving to shape GMO research practices; they will also be encouraged to consider the potential implications this has for future risk management policy.

\section{INTRODUCTION}

New Zealand is known around the world as a country that is "I $00 \%$ Pure." While this portrayal of an untouched landscape is particularly associated with a tourism marketing campaign [I], many New Zealanders also identify with this "clean green" image [2]. Efforts to maintain New Zealand's environmental integrity are therefore often high on the sociopolitical agenda, as evident in the country's long-standing "Nuclear-Free" stance [3], and its recent drive to become "Predator Free" [4].
Consistent with this "clean green" identity, many are proud to label New Zealand as "GE Free" [2]. Nevertheless, genetic engineering (GE) techniques are commonly used in New Zealand-based biotechnology research. The use of these techniques to develop genetically modified organisms (GMOs), particularly in agriculture, is especially contentious ${ }^{1}$. The importance of primary industries to the New Zealand economy means that there are not only significant benefits that could result from GMO research [6], but also significant costs [7]. As a result, there is controversy and debate that extends across the political, social, economic and scientific communities over the place of GMO research in New Zealand.

This paper provides a case examination of the controversy over GMO research in New Zealand. It is situated within an extensive literature that has charted the rise of such controversy worldwide following the emergence of commercial developments of GMOs in the late twentieth century [8-I I ]. The approach taken follows others in the

I. The definition and use of the terms "GM" and "GE" are themselves a matter of contention. For a detailed consideration of the debate surrounding these terms with a particular emphasis on the New Zealand context, see Ref [5]. For the purpose of this article, I will refer to the products of biotechnology research that are regulated under New Zealand legislation as "GMOs," thereby following the terminology used in this legislation (see HSNO Act, I996, section 2). In contrast, I will refer to groups and individuals that take action against such research as "GE-Free activists," thereby following their self-identification with this term [s].

Case Studies in the Environment, 2017, pps. I-8. electronic ISSN 2473-95 10. ( 2017 by the Regents of the University of California. All rights reserved. Please direct all requests for permission to photocopy or reproduce article content through the University of California Press's Reprints and Permissions web page, www.ucpress.edu/journals.php?p=reprints. DOI: https://doi.org/10.1 525/cse.201 7.000547 
field of Science and Technology Studies that explore the politics of scientific change and conflict [9, I 2 ], including, more specifically, those who use the methodological tools associated with Actor-Network Theory to explore sociotechnical controversies [ [ 3,14$]$. Although these approaches are not aimed at resolving such controversies, they provide important insights into the complex relationships involved in constructing them [14]. As such, we are asked to focus on the intricate details of what is being done, where it is being done, and the multitude of people and things involved in doing it. By tracing these relations, we can also consider what could (or should) be done differently, and the consequences of future (in)action [I 5 ].

In this case examination, I will outline key aspects of the controversy over GMO research studies that have occurred over the course of the last twenty years. As such I will focus on "particular episodes and on particular issues" [ I 3, p. 6] that are evident in the wealth of data available during this time period. These data include written documents associated with government legislation, decisionmaking processes, public debate, and GE-free activism. I will also draw on interview data collected as part of a broader programme of research exploring GMO research practices in New Zealand (see Ref [ I 6] for further details). By tracing the relations within and between these sources of evidence, I will ask how a variety of interacting factors have served to shape what is included in-and excluded from-the controversy over GMO research in New Zealand. This analysis will enable me to consider how this controversy is influencing GMO research practices, before finally speculating on the implications this has for future risk management policy.

\section{CASE EXAMINATION}

\section{Governing GMO Research: The Legislative Context}

The late twentieth century saw rapid growth of the biotechnology industry in New Zealand, including the development of GMOs. Although no GMOs were released into the environment, there were a number of indoor and outdoor research programmes, with the first field test conducted in 1988 [ 17 ].

While this early growth in research capabilities was accompanied by some independent oversight and regulation, such measures were relatively piecemeal and had no statutory basis [ 18 ]. Ultimately, the need for a coherent approach to the governance of GMO research practices led to the enactment of the Hazardous Substances and New Organisms (HSNO) Act in 1996. GMOs are defined as "new organisms" under this Act (section 2A) and are therefore subject to the rules governing new organisms that came into effect from July 1998.

This legal definition of GMOs as "new organisms" provides the statutory basis for GMO research as a biosafety concern, and therefore a risk that must be managed. Biosafety "addresses the technologies and practices that are implemented to prevent the unintentional exposure to humans or the accidental release of [new] organisms into the wild" [ 19, p. 304]. As such, there is a directive to restrict GM material to a specific, predetermined location. This level of restriction depends on the type of approval granted by the Environmental Protection Authority (EPA; previously the Environmental Risk Management Authority [ERMA]).

There are four main types of approval under which a GMO can exist in New Zealand (see HSNO Act, 1996, section 27). The first two apply to research conducted within a containment facility, where the risk of GM material escaping is closely managed. A "development in containment" is usually conducted inside (i.e in a laboratory), but can be conducted outside for GM animal research. A "field test" is conducted in an outdoor containment facility in order to assess the performance of a GMO under less-controlled environmental conditions. In addition to these two categories of contained research there are two categories of release, where biosafety is arguably not a dominant concern. In a "conditional release" GMOs are grown outside a containment facility but must be confined to a specific geographic area and have the potential to be recalled entirely. Finally, the "release" of a GMO, is applicable to commercial use as it can be New Zealand wide with no provisions for recall necessary.

New Zealand's status as a GE-free food producing nation is possible because, to date, there has not been a "release" or "conditional release" of a GMO. This is particularly significant, given the country's reliance on food exports, the premium commanded by GE-free foods in overseas markets, and the associated financial impacts that could result from GMO releases within New Zealand [7, 20]. Nevertheless, a variety of GMO research programmes have been conducted within containment facilities. It is here that the battle lines appear to be drawn in the controversy over GMO research: while many New Zealanders accept the use of indoor facilities for GMO research, the 
use of outdoor facilities is particularly contentious and is viewed by many as analogous to a "release." In the following sections, I will explore this apparent separation in detail by considering a variety of instances in which the use of outdoor containment facilities has been central to the controversy over GMO research in New Zealand.

\section{Debating GMO Research: The Royal Commission on Genetic Modification}

Although the HSNO Act was intended as a coherent approach to the management of GMO research practices, it did little to allay public concerns over this rapidly expanding area of biotechnology. The late r 990 os was punctuated by various forms of civic actions taken against the presence of GMOs in New Zealand's food and environment, including public demonstrations and the declaration of GE-free zones around the country [2 I ].

Many questions that surrounded GMO research became a political issue in the buildup to the 1999 general election [22]. In 1998, the Green Party-a political party in New Zealand-launched a campaign to raise public awareness on the topic of GE. During this campaign, the party co-leader Jeanette Fitzsimmons spoke to community groups around the country and issued numerous press releases [23]. These focused on the need to preserve New Zealand's clean green image and the potential threat posed by GMO research.

Right now, before these experiments reach commercial production, is the last chance this country has to say to the world, 'We are genetic engineering free, just as we are nuclear free. [24]

During this campaign, the Green Party launched a petition for a Royal Commission of Inquiry, the highest level government-led inquiry possible in New Zealand. They also called for a moratorium on GMO field releases and tests. The petition-signed by 92,000 people-was submitted to parliament in October 1999 [25]. After the November election, the incoming government signalled that it would establish a Royal Commission on Genetic Modification (RCGM) and impose a moratorium on field releases; a moratorium on field tests was encouraged on a voluntary basis [25]. The Green Party indicated that it was "satisfied" with the terms of reference for the inquiry and the moratorium on releases, although it was "very disappointed with lack of moratorium on field trials" [23].
The RCGM began in May 2000. It was a survey of the present and future options available to New Zealand with regards to GM technology, and any legislative or institutional changes that would be necessary in order to pursue these options [ 17 ]. In all, over I 0,000 New Zealanders contributed to the RCGM process [1 8], including members of the general public as well as representatives of special interest groups [25].

During the course of the inquiry, it was evident that the public placed great value on the "clean green" image of New Zealand, and outdoor research posed a particular threat to this.

Those members of the public who participated in the public meetings or made written submissions showed a strong sense of conviction that the interests of the country would be best served by maintaining our "clean green" image. People were more open to the use of genetic modification in contained research and for medical purposes. [I7, p. 7]

Others were prepared for research to continue in containment, but were more concerned about field tests (trials) or release into the environment. Their main concern was the safety of the environment. [I7, P.III]

Despite these concerns, the commissioners upheld the HSNO definition of field testing as a form of contained research [17, p. 1 22]. Their overall conclusion of "preserving opportunities" $[17, \mathrm{p} .33 \mathrm{I}]$ stressed the benefits that GMO research could yield if it was allowed to proceed under the regulatory framework provided by the HSNO Act. Furthermore, although they acknowledged the value of New Zealand's "clean green" image, the commissioners concluded that it would not be threatened by the development of GMOs in outdoor settings [ 17, p. 332]. This sentiment was underlined by the government's decision to lift the voluntary moratorium on GMO field tests soon after the RCGM was concluded (in October 200I) and the moratorium on releases two years later (in October 2003) [18].

\section{Taking Action Against GMO Research: Beyond the Royal Commission}

The RCGM's decision not to recommend a completely GE-free New Zealand, which included the acceptance of outdoor GMO research, was met with dismay by numerous individuals and public interest groups who had taken part in the inquiry $[26,27]$. The period directly following 
the RCGM was therefore a time when members of the public searched for other means to express their views and take action against GMO research [2I, 28]. The Green Gloves Pledge, for example, was signed by 3,000 New Zealanders who promised:

To take non-violent but direct action to prevent the irreversible release of genetically engineered lifeforms into the New Zealand environment whether this is deemed illegal or not. [29]

This pledge to take "direct action" involved the sabotage of crops and was targeted not only at releases but also at GMO field tests around the country. One prominent group associated with these activities - the People's Moratorium Enforcement Agency-was comprised of people who were frustrated that their formal protests against GMO research had not been listened to. As a result

they have moved to take matters into their own hands. This month they held a camp with the express purpose of 'training activists in direct action techniques... They learned how to blockade trucks and trains carrying GM produce and how to make life difficult for those trying to end the protests... Crucially they also learned how 'decontamination' [destruction of crops] should be undertaken to minimise the risks of GM material spreading further into the environment. [30]

The training camp mentioned in the above quotation was targeted at a field trial of GM onions at Crop and Food Research, a New Zealand Crown Research Institute. Although there is no evidence that the skills learned at this particular training camp were ever put to use, Crop and Food Research was the victim of sabotage in 2002, when a potato crop was destroyed [30]. Another Crown Research Institute, Scion, has also reported incidents at its GM Pine tree facility in 2008 [3 I] and $20 \mathrm{I} 2$ [32].

Numerous other individuals and groups, though not necessarily advocates of such radical activities, nevertheless actively campaign against outdoor GMO research, choosing to use the popular media, protest marches, or even court cases to voice their concerns [2 I, 28]. In contrast to the "direct" sabotage of crops, these relatively "indirect" actions make use of democratic processes to target specific field test applications, although these actions can themselves take a variety of forms.

Under section 53 (I) (d) of the HSNO Act, field test applications must be publicly notified, and written and oral submissions must be considered before a decision is made on the application. Although the submissions process is intended for the consideration of specific details of the research proposal under application, submitters also use it as an opportunity to dispute the use of outdoor containment facilities more generally. This is evident in submissions made against an application to field test GM onions, which was lodged by Crop and Food Research in April 2008 [33]. In many of the submissions, the GM onion research itself was not specifically debated; instead, the field was the object of conflict. The legal definition of the field as a containment facility did little to assuage their fears that outdoor research would contaminate the New Zealand environment.

$N Z$ is a 'GE free' country at the moment and, as such, enjoys substantial trade benefits which will be lost should GE crops be grown outside the laboratory. (Submission ID 9954)

It is paramount that we safeguard NZ's unique position as solitary GE Free first world ag producer - this gives us a tremendous advantage for our products with consumers who increasingly are rejecting genetic modification of food.

There is an absolute need to have only the complete confinement of any GE trials. (Submission ID 9g82)

Ultimately, ERMA did not align itself with these views in its final decision, simply noting that "Several submitters... expressed concerns about allowing field tests of genetically modified organisms," but that the decisionmaking committee was "satisfied that all of the concerns have been adequately addressed by the evidence and material considered" [34, p. 6].

Nevertheless, although this particular field test application was approved, the research has not commenced. The reason for this appears to be another form of indirect action: the informal monitoring of GMO field tests, which is regularly undertaken by GE-free activists.

\section{[The president of GE Free NZ] accused authorities of being slack in their monitoring of field trials, and said the organisation maintains visual and photographic reports of all field trials in the country. [35]}

It was during a visit to a field test of GM brassicas at Crop and Food Research that a breach of containment conditions was detected. The discovery initiated a chain of events that ultimately led to the discontinuation of all 
GMO field tests at this research institution [36], including the recently approved GM onion research.

Public action against outdoor GMO research has recently entered another phase. Some local communities have taken action to prevent all outdoor research and releases of GMOs by using planning mechanisms under the Resource Management Act (1991) [37,38]. Although this move to regulate GMO research at the local level using non-HSNO legislation is itself a controversial matter $[39,40]$, it is nevertheless another instance in which outdoor containment facilities are central to the controversy over GMO research in New Zealand.

\section{Doing GMO Research: Progress Amidst the Controversy}

Taken collectively, these various instances of controversy over the use of outdoor containment facilities appear to be having a significant effect on GMO research practices. Since 1988 , a total of 57 outdoor GMO experiments have been approved and subsequently commenced; of these, only I 2 have occurred under HSNO legislation [2 I, 4I]. Given that there is an observable decline in the number of applications that have been lodged across this period [2I, p. 6I], it would appear that research institutions are themselves deciding not to conduct outdoor research. Although representatives of the biotechnology industry acknowledge this is the case, official explanations are often framed in terms of regulatory barriers under the HSNO Act $[42,43]$. Privately held views, however, recognise other influences.

I don't think it's the ease of... whether or not... how easy the [application] process is I mean the expense is one thing but it's also the public perception thing that goes with it about whether or not you want to go ahead with it or whether you're going to do it... the trial offshore or whether you're going to keep it in the lab and do more on it in a glasshouse or something so... I don't think it's the ease or difficulty. (Interview E)

The role played by the public in the decline of outdoor research activities has been highlighted elsewhere $[28,44]$. What are not considered in such analyses are the consequences of this situation. As the above quotation indicates, a research institution's decision not to conduct a GMO field test should not be taken as an indication that they are not conducting any GMO research. There are other ways of furthering a research programme: one option is to "keep it in the lab." The relative acceptability of indoor research means that research institutions and individual scientists alike are not exposed to the level of public scrutiny associated with outdoor research, and there is therefore much less chance that their reputations will be damaged [ 16 ]. As a result, indoor research can proceed, and potentially thrive, despite the controversy surrounding outdoor research.

It is important to note that indoor facilities are becoming increasingly complex and sophisticated, and arguably blur the distinction between the laboratory and the field. One such facility, the "Biotron" at Lincoln University in Canterbury:

is essentially an encased and biologically secure, climatecontrolled laboratory unit that duplicates, on a small scale, an exterior growing environment ...The beauty of it is that it bridges the gap between the complexity of real field communities of plants, insects and micro-organisms and the simplicity of laboratory or greenhouse experiments. [45]

Although they are technically "indoors," these facilities can only function through constant interactions with the "outdoors": for example, to enable soil to be brought in and out of the facility, or for service engineers to maintain equipment [ 16$]$. If proper procedures are not followed in the course of these interactions, GM material could easily escape into the outside environment.

Even the most modern [containment] laboratory would almost certainly experience a containment breach if the correct procedures and protocols aren't followed. (Interview $N$ )

As such, there are significant risks associated with GMO research conducted in indoor containment facilities. Nevertheless, very little attention is being paid to these risks, and this is arguably a result of the overt focus on the risks associated with outdoor research [16]. Are people aware of this when they argue for a GE-free New Zealand? It is likely that the complexities of this situation will remain hidden as long as the use of outdoor containment facilities remains central to the controversy over GMO research in New Zealand.

These observations have implications for future GMO risk management policy. Current policy analysis asks whether New Zealand has the capacity to make decisions on outdoor GMO research and releases [2I]. But it is equally important to question whether New Zealand has the capacity to manage the risks associated with the poten- 
tial growth and increased complexities of indoor GMO research. Recent changes to decision-making pathways for indoor research could actually be undermining the ability of research institutions to manage the risks associated with GMO research [16]. It is time to reconsider the risks associated with indoor research, rather than assume that the lack of controversy that surrounds them is an indication of the "safety" that they can provide.

\section{CONCLUSIONS}

The controversy over GMO research in New Zealand is having a significant effect on research practices. The HSNO Act defines outdoor facilities as capable of containing GMOs and prevents the spread of GM material into the wider New Zealand environment. However, ongoing public controversy is successfully contesting the status of outdoor containment facilities, and research institutions are ultimately choosing not to conduct outdoor research.

But a GE-free New Zealand nevertheless creates space for GMO research-in the relative seclusion provided by indoor facilities. This has implications for the risk management of GMO research, and it is therefore vital to shift our attention to these hidden spaces rather than simply follow the direction of public controversy.

\section{CASE STUDY QUESTIONS}

I. Would you describe New Zealand as "GE Free"? Explain your answer.

2. Explain how each of the following factors are involved in, and serve to shape, the controversy over GMO research in New Zealand:

- Legislation and associated decision-making processes

- Formal methods of public consultation

- GE-free activists

3. How have the above factors influenced GMO research practices in New Zealand? What implications could this have for the future?

4. Environmental policy often has to deal with uncertainties regarding the risks and benefits of new technologies. In this case study, how has uncertainty over GMO research shaped the imple- mentation of policy? Can you think of other examples where scientific uncertainty has influenced the implementation of policy?

5. This case study highlights aspects of GMO research that are hidden by the overt public controversy surrounding this matter. What insights do these observations give you into other sociotechnical controversies worldwide (for example, in your home country)?

\section{AUTHOR CONTRIBUTION}

The author collected all the data and wrote the entire article.

\section{ACKNOWLEDGEMENTS}

This paper is based on $\mathrm{PhD}$ research that was supervised by Roy Montgomery and Suzanne Vallance at Lincoln University. The author thanks Ann Brower, Nick Kirk, and two anonymous referees for comments on earlier drafts of this article.

\section{FUNDING}

This paper is based on $\mathrm{PhD}$ research that was funded by a William Machin Doctoral Scholarship at Lincoln University.

\section{COMPETING INTERESTS}

None

\section{REFERENCES}

I. Cloke P, Perkins HC. Cracking the canyon with the awesome foursome: representations of adventure tourism in New Zealand. Environ Plann D Soc Space. 1998; 16(2): 185-2 I 8.

2. Coyle F, Maslin C, Fairweather J, Hunt L. Public understandings of biotechnology in New Zealand: nature, clean green image and spirituality. Agribusiness and Economics Research Unit, Research Report No. 265. Lincoln University, New Zealand; 2003.

3. Newshub.co.nz. New Zealand 30 Years Officially Nuclear Free; 2017. Available: http://www.newshub.co.nz/home/newzealand/2017/06/new-zealand-30-years-officially-nuclearfree.html. Accessed o9 June 2017.

4. Department of Conservation. Predator Free 2050; 2017. Available: http://www.doc.govt.nz/predator-free-2050. Accessed 09 June 2017. 
5. Tucker C. Making resistance politics: the opposition to genetic engineering in Aotearoa New Zealand. Unpublished PhD Thesis, Massey University, New Zealand; 20 I I.

6. West A. The Dwindling Strategic Options Facing New Zealand's Biological Economy. In: Rowarth JS, Sutherland GP, editors. The Role of the Primary Resources in New Zealand's Economic Revival: Proceedings of the Primary Resources Forum, 27 June 200 I, Christchurch, New Zealand. The Royal Society of New Zealand; 200 I. pp. 44-49.

7. Campbell H, Fitzgerald R, Saunders C, Sivak L. Strategic Issues for GMOs in Primary Production: Key Economic Drivers and Emerging Issues. Dunedin, New Zealand: University of Otago; 2000.

8. Devos Y, Maeseele P, Reheul D, Speybroeck LV, Waele DD. Ethics in the societal debate on Genetically Modified Organisms: A (re)quest for sense and sensibility.J Agric Environ Ethics. 2008;2 I (I): 29.

9. Jasanoff SS. Designs on Nature. Science and Democracy in Europe and the United States. Princeton and Oxford: Princeton University Press; 2005.

го. Newell P. Trade and biotechnology in Latin America: democratization, contestation and the politics of mobilization. $J$ Agrar Change. 2008;8(2-3): 345 .

I I. Yamaguchi T, Suda F. Changing social order and the quest for justification: GMO controversies in Japan. Sci Technol Hum Values. 2010;35(3): 382-407.

I2. Callon M, Lascoumes P, Barthe Y. Acting in an Uncertain World. An Essay on Technological Democracy. Cambridge, MA: The MIT Press; 2009.

1 3. Hinchliffe S. Indeterminacy in-decisions-science, policy and politics in the BSE (Bovine Spongiform Encephalopathy) crisis. Trans Inst Br Geogr. 200 I ;26(2): I 82-204.

I4. Venturini T. Diving in magma: how to explore controversies with actor-network theory. Public Understanding Sci.2010;19(3): 258-273.

15. Mol A. Ontological Politics. A Word and Some Questions. In: Law J, Hassard J, editors. Actor Network Theory and After. Oxford: Blackwell; 1999. pp. 74-89.

16. Edwards S. Doing actor-network theory: integrating network analysis with empirical philosophy in the study of research into genetically modified organisms in New Zealand. Unpublished PhD Thesis, Lincoln University, New Zealand; 2014. Available: http://researcharchive.lincoln.ac.nz/handle/ I $0182 / 6744$

17. Royal Commission on Genetic Modification. Report of the royal commission on genetic modification; 200 I. Available: http://www.mfe.govt.nz/publications/hazards/report-royalcommission-genetic-modification. Accessed I 3 June 20 I 7.

ı 8. Pollak D. Clean, green and genetically modified? GMOs and the future of New Zealand. Ian Oxford Fellowship Report; 2003. Available: https://www.fulbright.org.nz/wp-content/ uploads/201 I/I 2/axford2003-pollak.pdf. Accessed I3 June 2017.

19. Hulme PE. Biosecurity: The Changing Face of Invasion Biology. In: Richardson DM, editor. Fifty Years of Invasion
Ecology: The Legacy of Charles Elton. Chichester, UK: Blackwell; 20 I I. pp. 30 I-3 I 4.

20. Saunders C, Kaye-Blake W, Cagatay S. Economic impacts on New Zealand of GM crops: result from partial equilibrium modelling. Research Report No. 26I, Agribusiness and Economics Research Unit, Lincoln University, New Zealand; 2003.

21. McGuinness Institute. An overview of genetic modification in New Zealand I 973-20 I 3: the first forty years; 2013. Available: http://www.mcguinnessinstitute.org/ project-2058-reports/. Accessed I 3 June 2017.

22. Rogers-Hayden T, Campbell JR. Re-negotiating science in environmentalists' submissions to New Zealand's Royal Commission on Genetic Modification. Environ Values. 2003; $12(4):$ 5 15-534.

23. Green Party of Aotearoa New Zealand. Green timeline on GE Royal Commission, \& reaction to the terms of reference; 2000. Available: https://home.greens.org.nz/press-releases/ green-timeline-ge-royal-commission-reaction-terms-reference. Accessed 24 May 2017.

24. Green Party of Aotearoa New Zealand. Canterbury NZ's genetic engineering cauldron; 1998. Available: https://home.greens.org.nz/press-releases/canterbury-nzsgenetic-engineering-cauldron. Accessed 24 May 2017.

25. Royal Commission on Genetic Modification. Appendix I: Context and Process; 200I. Available: http://www.mfe.govt.nz/publications/hazards/report-royalcommission-genetic-modification. Accessed I 3 June 2017.

26. Goven J. Processes of inclusion, cultures of calculation, structures of power: scientific citizenship and the Royal Commission on Genetic Modification. Sci Technol Hum Values. 2006;3 I (5): 565 .

27. Rogers-Hayden T. Asilomar's legacy in Aotearoa New Zealand. Sci Cult. 2005; i 4(4): 393-4 Io.

28. Tucker C. Using social network analysis and framing to assess collective identity in the genetic engineering resistance movement of Aotearoa New Zealand. Soc Mov Stud. 20I3; I 2(I): 8I-95.

29. Green Gloves. Green Gloves direct action pledge; $200 \mathrm{I}$. Available: http://www.scoop.co.nz/stories/POo I I /Soo I 86/ green-gloves-direct-action-pledge.htm. Accessed 16 December 2014.

30. Nippert M. Anti-GM troops set for action; 2004. Available: http://www.nzherald.co.nz/nz/news/ article.cfm?c_id $=$ I \&objectid $=3544$ I 50 . Accessed I 3 June 20 I 7. 31. Newshub.co.nz. Lobby group demands controls for GM tree trialing; 2008. Available: http://www.newshub.co.nz/ nznews/lobby-group-demands-controls-for-gm-tree-

trialing-20080 I I 6 I I. Accessed I 3 June 2017.

32. Stuff.co.nz. Hundreds of GM trees destroyed; 2012. Available: http://www.stuff.co.nz/national/6735584/ Hundreds-of-GM-trees-destroyed. Accessed I 3 June 20 I 7.

33. Crop and Food Research. Application for field test of genetically modified onions, garlic and leeks with altered 
agronomic or quality traits; 2008. Available: http://www.epa.govt.nz/search-databases/

HSNO\%20Application\%2oRegister\%2oDocuments/

GMFo6002\%20application.pdf. Accessed I 3 June 2017.

34. Environmental Risk Management Authority. Decision on

application GMFo6002; 2008. Available:

http://www.epa.govt.nz/Publications/

GMFo6002-decision.pdf. Accessed I 3 June 2017.

35. Harper P. Scion GM pine trees destroyed by vandals (update); 20 I 2. Available: http://www.nzherald.co.nz/rotoruadaily-post/news/

article.cfm?c_id $=$ I 503438 \&objectid $={ }_{\text {I }}$ 1059993. Accessed 26 September 2013.

36. Williams D. Watchdog wants role in GM trials; 2009. Available: http://www.stuff.co.nz/the-press/news/3020078/ Watchdog-wants-role-in-GM-trials. Accessed I 3 June 2017.

37. Hawke's Bay Today. Hastings District goes GM-Free; 2015. Available: http://www.nzherald.co.nz/hawkes-baytoday/news/article.cfm?c_id= I 503462 \&objectid= I I 5 I 2 I 35 . Accessed I 2 June 2017.

38. Soil and Health Association. Auckland to stay GE Free under new Unitary Plan; 2016. Available: http://www.scoop.co.nz/stories/AKI 608/Soo765/aucklandto-stay-ge-free-under-new-unitary-plan.htm. Accessed I 2 June 2017.
39. New Zealand Government. Govt to review role of councils with GMOs; 2016. Available: http://www.scoop.co.nz/stories/PA I 609/So0027/govt-toreview-role-of-councils-with-gmos.htm. Accessed I 2 June 2017. 40. Soil and Health Association. GE-Free zones under threat from RMA Amendment; $2017 . \quad$ Available: https://organicnz.org.nz/media-releases/ge/ge-free-zonesthreat-rma-amendment/. Accessed I 2 June 2017.

4I. Environmental Protection Authority. Field tests and outdoor developments of genetically modified organisms; 2017. Available: http://epa.govt.nz/new-organisms/popular-notopics/Pages/GM-field-tests-in-NZ.aspx. Accessed I 3 June 2017.

42. Rolleston W. An industry viewpoint - why it's time to relax the regulations. AgScience. 2010 ; (36): 7-9.

43. Stewart A, Woodfield D. A plant breeder's view of genetic modification. AgScience. 2010 ;(36): I I - I 2.

44. Sustainability Council. Citizen's arrest: accounting for GM food's arrested development; 2012. Available: http://www.sustainabilitynz.org/citizens-arrest-accountingfor-the-arrested-development-of-gm-foods/. Accessed I 3 June 2017.

45. Collins I. Lincoln Biotron gives NZ 'powerful research tool'; 2004. Available: http://livingheritage.lincoln.ac.nz/ nodes/view/7574. Accessed 27 May 2017. 